
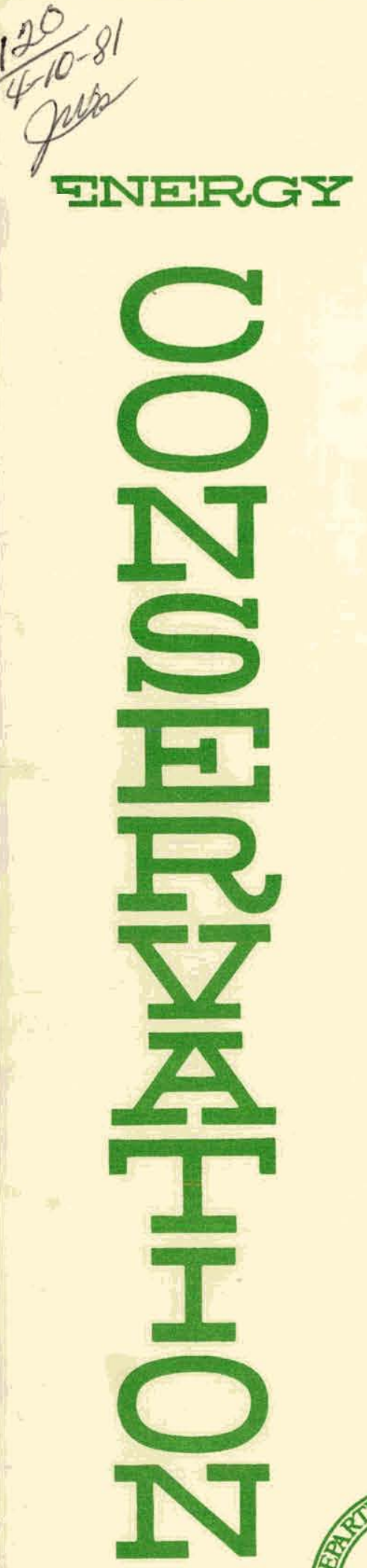

\title{
DESIGN AND DEVELOPMENT OF STIRLING ENGINES FOR STATIONARY POWER GENERATION APPLICATIONS IN THE 500 TO 3000 HORSEPOWER RANGE
}

Volume 2: Program Plan<smiles>CCCCCCC(C)C</smiles>

September 15,1980<smiles>CC=CC(C)(C)OC(C)=O</smiles>

Work Performed Under Contract No. AC02-79ET15207

Advanced Mechanical Technology, Incorporated Newton, Massachusetts

\section{U. S. DEPARTMENT OF ENERGY}




\section{DISCLAIMER}

This report was prepared as an account of work sponsored by an agency of the United States Government. Neither the United States Government nor any agency Thereof, nor any of their employees, makes any warranty, express or implied, or assumes any legal liability or responsibility for the accuracy, completeness, or usefulness of any information, apparatus, product, or process disclosed, or represents that its use would not infringe privately owned rights. Reference herein to any specific commercial product, process, or service by trade name, trademark, manufacturer, or otherwise does not necessarily constitute or imply its endorsement, recommendation, or favoring by the United States Government or any agency thereof. The views and opinions of authors expressed herein do not necessarily state or reflect those of the United States Government or any agency thereof. 


\section{DISCLAIMER}

Portions of this document may be illegible in electronic image products. Images are produced from the best available original document. 


\section{DISCLAIMER}

"This book was prepared as an account of work sponsored by an agency of the United States Government. Neither the United States Government nor any agency thereof, nor any of their employees, makes any warranty, express or implied, or assumes any legal liability or responsibility for the accuracy, completeness, or usefulness of any information, apparatus, product, or process disclosed, or represents that its use would not infringe privately owned rights. Reference herein to any specific commercial product, process, or service by trade name, trademark, manufacturer, or otherwise, does not necessarily constitute or imply its endorsement, recommendation, or favoring by the United States Government or any agency thereof. The views and opinions of authors expressed herein do not necessarily state or reflect those of the United States Government or any agency thereof."

This report has been reproduced directly from the best available copy.

Available from the National Technical Information Service, U. S. Department of Commerce, Springfield, Virginia 22161.

Price: Printed Copy A04 Microfiche A01 


\title{
DESIGN AND DEVELOPMENT OF STIRLING ENGINES \\ FOR STATIONARY POWER GENERATION APPLICATIONS \\ IN THE 500 TO 3000 HORSEPOWER RANGE
}

\section{VOLUME 2: PROGRAM PLAN}

$$
\text { Prepared for: }
$$

Argonne National Laboratory

Components Technology Division

Prepared by:

ADVANCED MECHANICAL TECHNOLOGY, INC.

141 California Street

Newton, Massachusetts 02158

September 15, 1.980

\author{
Sponsored by: \\ Department of Energy \\ Assistant Secretary for Fossil Energy \\ office of Coal Utilization
}




\section{Acknowledgement}

This study was sponsored by the Division of Fossil Fuel Utilization, Department of Energy under contract No. DE-AC02-79ET15207. The guidance and support of John Neal and Warren Bunker of DOE are gratefully acknowledged. Kenneth Uherka, the Technical Project Monitor, and Robert Holtz, Manager of Heat Utilization Section in the Components Technology Division, both of Argonne National Laboratory provided valuable advice and technical guidance.

The prime contractor was Advanced Mechanical Technology, Inc. of Newton, Massachusetts. The principal authors from AMTI were: Mark Schuetz, Project Engineer; Dr. Joseph Gerstmann, Vice President and Program Manager; and Dr. Lawrence Hoagland, Director of Research; with assistance from Dr. Walter Syniuta, President; Rolf Krisher, Design Engineer; and Cyril Randall, Chief Design Engineer.

The principal subcontractor in the area of Stirling engine design was K.B.. United Stirling (Sweden) AB\& Co. Christer Bratt and John Berntell were the principal contributors to the project. Bengt-Ove Moodysson, Herbert Nilsson, Stig Gummesson and Lars Sjoestedt also contributed. Ricardo Consulting Engineers, Ltd. of England were engaged as consultants to United Stirling in the area of engine design. The prircipal contributor from Ricardo was V.C.H. Pope, with additional contributions from I.D. Johnstone, C:M. Andrews, and A.R. Crouch. 
Thermacore; Inc. of Leola, Pennsylvania were subcontractors in the area of heat pipe design. Donald Ernst was responsible for their contribution.

The following consultants assisted Advanced Mechanical Technology, Inc.: Worth Percival (of United Stirling, Inc., Alexandria, VA); Frank Pompei, Pompei Associates; Adel Sarofim, Massachusetts Institute of Technology; and Robert Baron, Energy \& Environmental Engineering, Inc.

We gratefully acknowledge valuable information provided by Curtis Novak of Riley Stoker Corp., and Ervin Lentz and David DeCoursin of Fluidyne Engineering Corporation.

Last but not least, we thank Joyce Carmen, Sandra Gerstmann and Merla Higgins for their tireless efforts to type this report. 
TABLE OF CONTENTS

\section{Section}

$\underline{\text { Page }}$

ACKNOWLEDGEMENT. ................................

TABLE OF CONTENTS..................................

LIST OF FIGURES ................................

1. INTRODUCTION AND SUMMARY $\ldots \ldots \ldots \ldots \ldots \ldots \ldots \ldots \ldots \ldots \ldots \ldots \ldots \ldots$

2. DETAILED PROGRAM PLAN...........................

2.1 SYSTEM DESIGN AND DEMONSTRATION.................2-2

2.1 .1 Task Descriptions...................... 2-2

2.1 .2 Schedule............................. 2-8

2.2 ENGINE DESTGN AND FABRICATION.................

2.2.1 Task Descriptions...................... 2-11

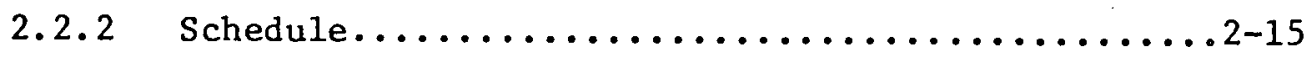

2.3 HEAT PIPE DESIGN AND FABRICATION................ 2-17

2.3.1 Work Descriptions..................... 2-17

2.3.2 Schedule............................2-20

2.4 COMBUSTION SYSTEM DESIGN AND FABRICATION............2-23

2.4.1 Task Descriptions....................2-23

2.4 .2 Schedule...........................2-29

2.5 SMALL ENGINE SYSTEM....................... 2-32

2.5.1 Task Descriptions...................... 2-32

2.5.2 Schedule...............................

3. DETAILED COST BREAKDOWN......................... 
Figure $\quad$ Page

Overall Program Plan with Key Milestones................. 1-4

2 Overall Program Cost by Phase........................

3 Overall Program Cost by Program Segment.................. 1-9

4 System Design and Demonstration....................... 2-9.

5 Engine Design and Fabrication..........................

6 Heat Pipe Design and Fabrication......................21

$7 \quad$ FBC Design and Fabrication...............................

8 Small Engine System........................... 2-37

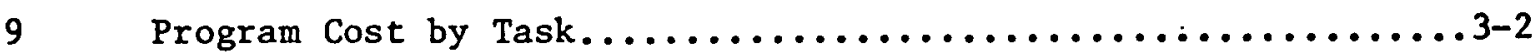




\section{INTRODUCTION AND SUMMARY}

A plan for implementing the proposed state-of-the-art design described in Volume I has been developed. The main objective of the project is to demonstrate a large coal-fired Stirling engine and thus shorten the lead time to commercialization. The demonstration engine will be based on the concepts developed in the first phase of this program, as detailed in Volume I of this report. Thus the proposed program plan is based on the U-4 engine concept fired by a fluidized bed combustor with a two-stage gravity-assisted heat pipe.

The plan is divided into five phases and an ongoing supporting technology program. Phase I, Conceptual Design, has been completed. The remaining phases are: Preliminary Design; Final Design; Fabrication; and Testing and Demonstration. The primary target is to begin testing the large coal-fired engine by the fifth year (1985) after the start of Preliminary Design.

While each of the major components in the system (Stirling engine, FBC, heat pipe) are considered state-of-the-art, the FBC/heat-pipe/ Stirling engine system is somewhat of a new application for each of che components, and thus some departure from the strictly conventional technology is to be expected, particularly in the FBC design. In order to provide the minimum technical risk in this large engine development program it is recommended that a smaller FBC/heat-pipe/Stirling system 
should be built as well. The small system should be built using a rugged, proven Stirling engine, such as the United Stirling P-40 engine, so as to avoid any need for engine development in the small system. Then, an FBC/heat-pipe system would be built to fire that engine.

The primary purposes of this small engine program would be to bring potential technical problems relative to the $\mathrm{FBC} /$ heat pipe/engine interfaces to the surface early in the large engine development program, to examine the system dynamics and controls requirements, and to provide a test bed for testing potential solutions to problems.

The proposed large engine development program assumes that the small engine system would be pursued. In fact, the final design of the coal-fired Stirling engine is allowed to extend into the third year in order to maximize the usefulness of small engine testing, which begins in the mrddle of the second year: Thus, the large engine design tasks are dependent on good results in the small engine system.

In addition to the small engine system and the large coal-fired engine system, it is recommended that a large liquid-fueled (direct-fired) engine should be built simultaneously. This engine would require a minimum of work beyond that which is required for a coal-fired engine, yet would be valuable from two points of view. First, this engine would be conceptually the same as the existing state-of-the-art Stirling engines. Thus, this engine would have a lower technical risk, and could provide a valuable testing ground for full-scale largé Stirling engine components. Secondly, tiils engine couid be a useful end in itself, particularly for use with coal-derived fuels such as coal liquids and low Btu gas. 
In the pages to follow, the overall program schedule will be discussed, and the interrelationship of the small engine system work, the large liquid fueled engine work, and the large coal-fired engine work can be seen.

\section{Overall Program Plan}

The overall program schedule with key milestones is shown in Figure 1. The program is divided into five phases: Conceptual Design (already finished), Preliminary Design, Final Design, Fabrication, and 'lesting and Demonstration. Each of these phases is described briefly below.

The Phase II preliminary design of the large engine system is divided into four major tasks: Preliminary System Design, Preliminary Engine Design, Preliminary Heat Pipe Design and Preliminary FBC Design. Although Phase II spans an 18 month period, the Preliminary System Design and Preliminary Engine. Design will be 12 months long, so as to allow an earlier start on the Final Engine Design and Final System Design.

During Phase II, the small engine system will be designed and fabricated. This will enable testing to commence during the final design of the large system (Phase III).

Another important milestone, shown at the end of Task 2:4.2, Cold Flow Experiments, is the testing and analysis of a large cold flow model of the FBC (an unfired full-scale model). The purpose of this experiment is to ald in the final design c. $f$ the FBC by providing fluid dynamic and mixing information about the proposed FBC. 
FY :

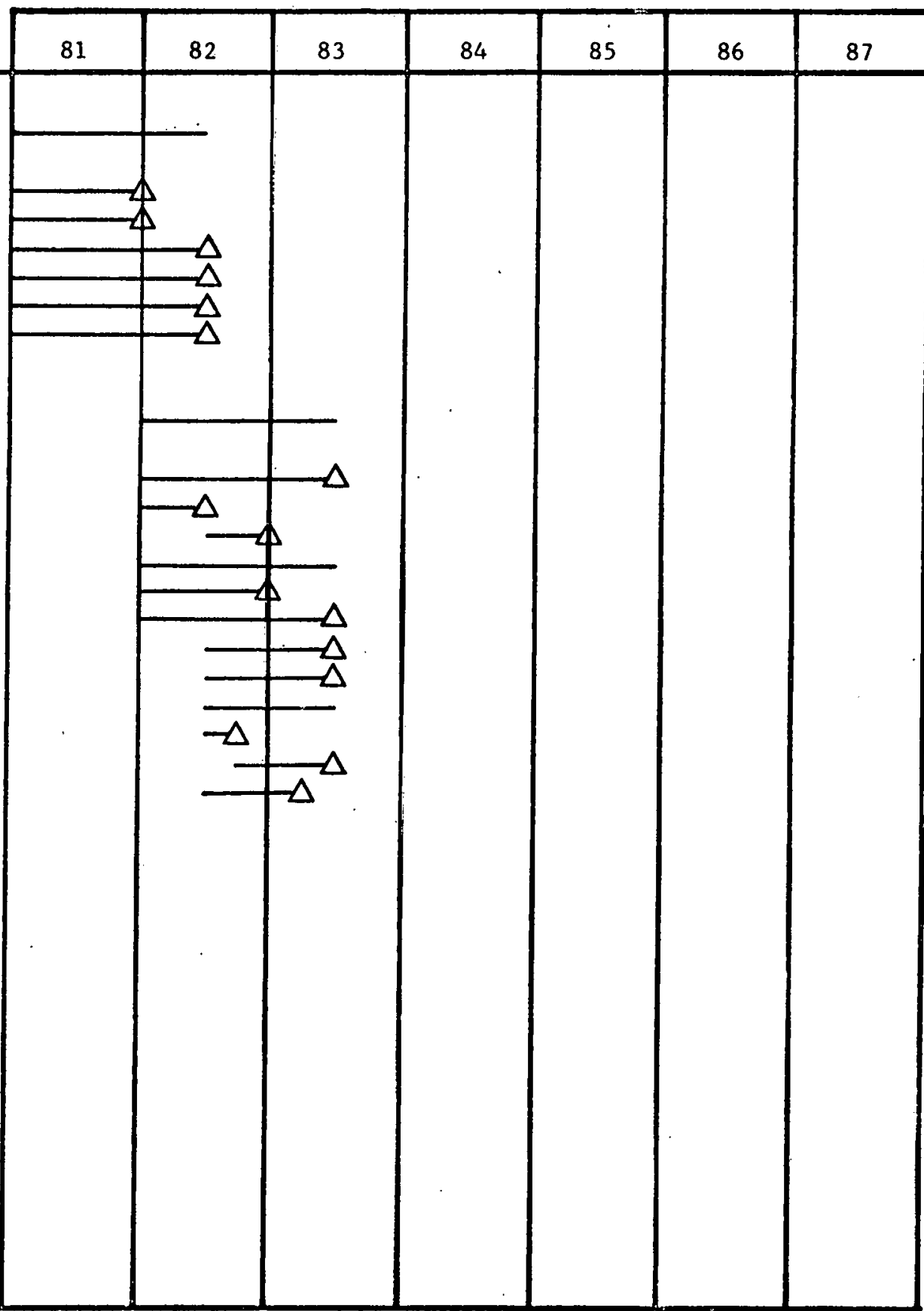

PHASE II: PRELIMINARY DESIGN

2.1 Preliininary System Design

2.2 Preliminary Engine Design

2.3 Preliminary Heàt Pipe Design

2.4 Preliminary FBC Design

2.4.2 Cold Flow Experiments

2.5 Design \& Fabricate - Smal $\dot{1}$ System

PHASE III: FINAL DESIGN

3.1 Final System Design

3.1.1 Final Process Design

3.1 .6 Site Plan

3.2 Final Engine Design

3.2.1 Final Engine Design - Direct Fired

3.2 .2 Final Engire Design - Coal Fired

3.3 Final Heat Pipe Design

Final FBC Design

3.5 Subsystem Tests - Small Systen

3.5.1 Install FBC and heat Pipes

3.5.2 Test FBC/Heat Pipes

3.5.3 Test Engine/Heat Pipe

FIGURE 1: OVERALL PROGRAM PLAN WITH 


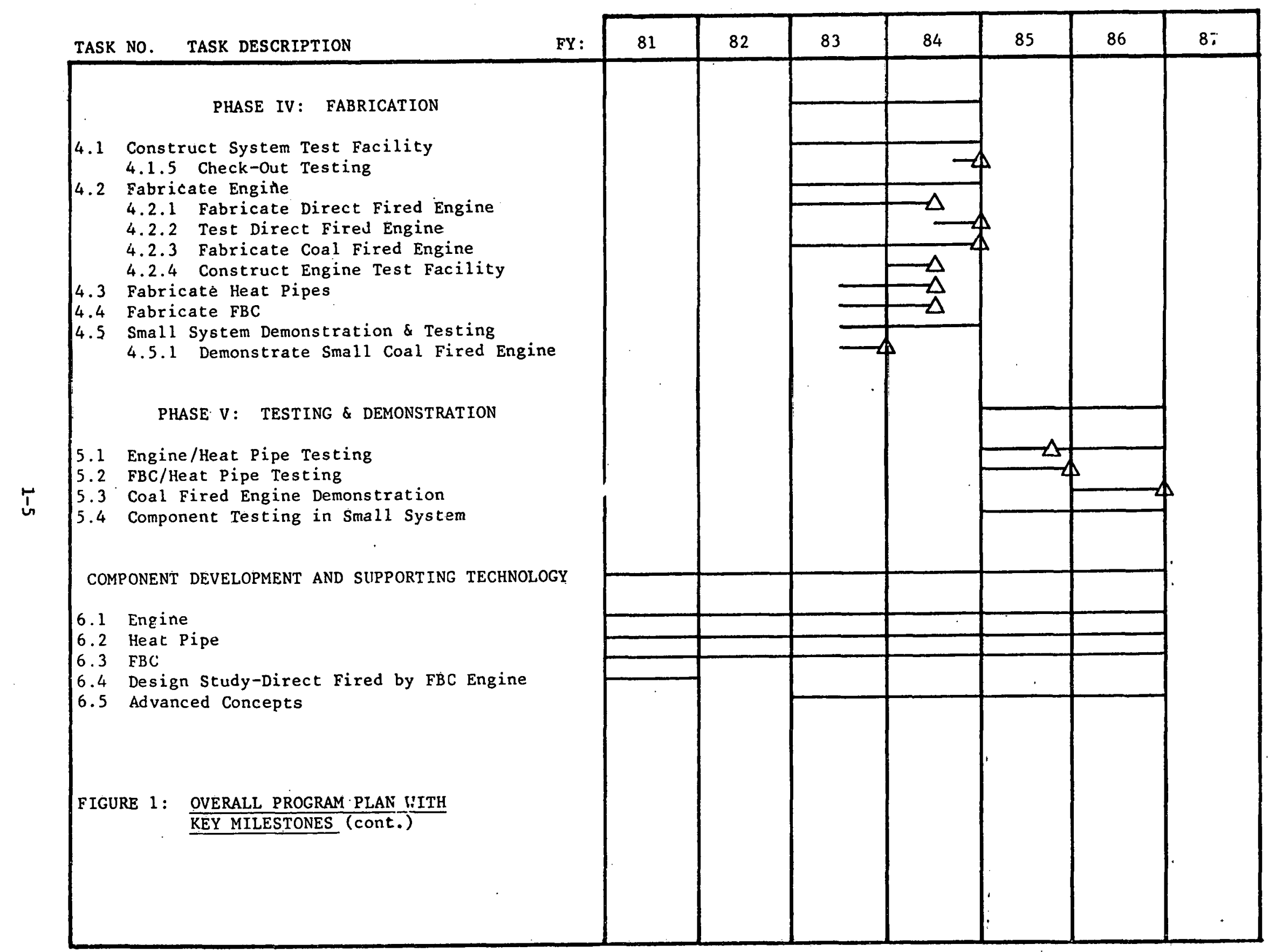


The final design phase will overlap the preliminary design phase by six months. As can be seen in Figure 1, the final system design and final engine design will begin in early 1982. It is felt that the fabrication time for these two subsystems will likely be longer than for the FBC and heat pipes, and thus the designs should proceed at a slightly faster pace. Furthermore, by allowing the final design of the FBC and heat pipes to proceed concurrently with the subsystem tests in the small system, maximum benefit may be derived from these subsystem tests, and greater confidence may be placed on the final designs of the FBC and heat pipes.

Another important point to note in Phase III is that the final design of the liquid fueled engine will be complete before the final design of the coal fired engine. In this way, the fabrication of long lead items such as large castings, etc., may begin early enough for assembly by 1985, yet the final design of the engine-heat pipe interface need not be finalized before experimentation on the smaller engine.

Once the site plan is complete (Task 3.1.6) then the bidding process for construction may be initiated. 'Two years are available for contractor selection, construction, fabrication or purchase of system components and their installation and check-out testing. In the meanwhile, the two large engines will be fabricated.

The liquid fueled engine :.s scheduled for completion in mid-1984 to allow six months of testing lefore completion of the coal fired engine. 
Thus, if any engine problems arise, they can be corrected before the coal fired engine is scheduled for testing.

Note that an engine test facility (Task 4.2.4) will be designed and fabricated by mid-1984. (Not to be confused with the system test facility, Task 4.1.) This facility will be suitable for liquid fuel engine testing initially, followed by electric testing of the heat pipe engine, and then further liquid fueled engine testing.

While the large FBC and heat pipes are being fabricated, the entire small engine system will be demonstrated. Following demonstration, scheduled for the end of 1983, the small engine facility would be used as a test-bed for components, materials, new concepts, etc.

In the final phase of the program, Phase $V$, the testing would proceed in a fashion similar to the small system tests, i.e., first the engine and heat pipe subsystem would be tested electrically while the FBC and heat pipes subsystem would be coal fired with water cooling of the secondary heat pipe. Following successful subsystem testing, the entire system would be assembled and tested as an integrated package.

Besides the tasks leading directly to the large coal fired engine demonstration, it is felt that a significant effort in Component Development and Supporting Technology will reduce much of the development risk, enabling the tasks on the demonstration path to proceed. without distraction. Included in these supporting tasks is Task 6.4, Design 
Study of FBC Direct Fired Engine. This is. not expected to impact the demonstration outcome, but is included here as it may affect the ultimate direction of FBC and Engine developments.

\section{Overall Program Costs}

The overall cost estimate by phase is outlined in Figure 2. Component Development and Supporting Technology is 1isted separately, even though the work occurs over the entire duration of the project.

The overall cost summary by program segment is shown in Figure 3 . In this breakdown, the Large Engine Program excludes any FBC development or Component Development and Supporting Technology.

The detailed breakdown of costs by task is shown in section 3 . 


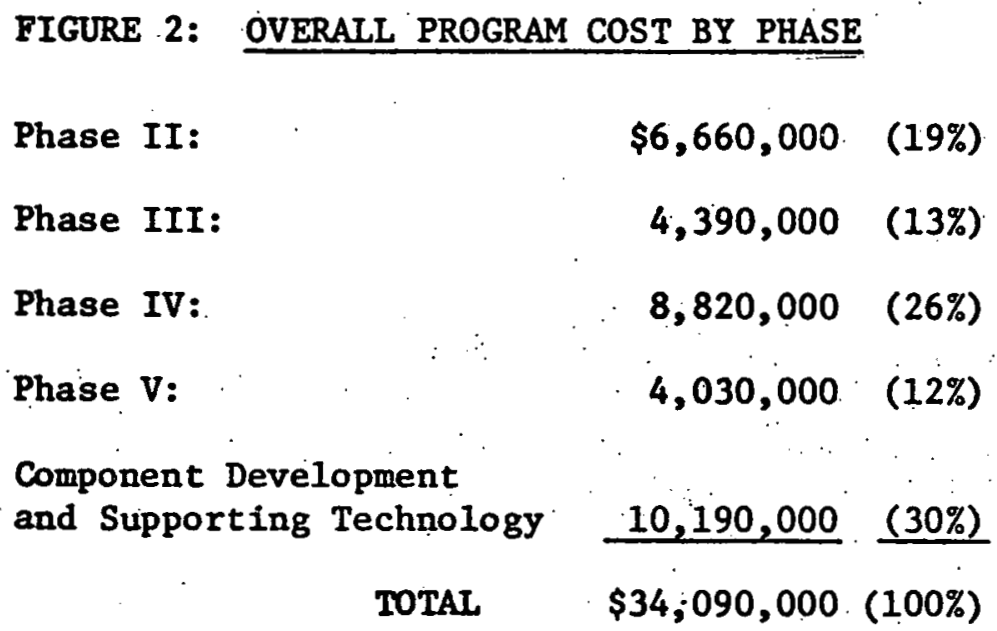

FIGURE 3: OVERALL PROGRAM COST BY

PROGRAM SEGMENT

Large Engine Program

(excluding FBC work)

$\$ 15,560,000 \quad(46 \%)$

Smal1 Engine Program

(Includes Tasks $2.5,3.5,4.5,5.4) \quad 4,790,000 \quad(14 \%)$

Large FBC Development

(Includes Tasks 2.4, 3.4, 4.4, 5.2, 6.3)

$6,270,000 \quad(18 \%)$

Component Development \&

Supporting Technology

(excluding FBC work)

$7,470,000 \quad(22 \%)$

TOTAL PROGRAM

$\$ 34,090,000$ (100\%) 


\section{DETAILED PROGRAM PLAN}

In this section, the detailed program schedule and the work statement for each program task are described. To facilitate understanding of the design and demonstration schedule, the program plan has been subdivided Into the following major task categories:

System Design and Demonstration

Engine Design and Fabrication

Heat Transport Design and Fabrication

Combustion System Design and Fabrication

Sma11 Engine Tests.

These are discussed separately below. The overall program outline and schedule is presented in the preceding section, 1. Introduction and Summary.

Before proceeding into the details, a few general comments are in order. First, it should be emphasized that the detailed plan has been prepared on the assumptions of a U-4 Stirling engine heated by a twostage gravity assisted heat pipe, which is heated by a coal-fired FBC. Furthermore, the small engine system is an integral part of the overall program, as is the Component Development and Supporting Technology work. The System Design and Demonstration section, the FBC Design and Fabrication section, and the Small Engine System section, were written by AMTI. United Stirling prepared the Engine Design and Fabrication Section, and Thermacore prepared the Heat Pipe Design and Fabrication Section. Because it is assumed that there will be a prime contractor and several subcontractors, the program management and reporting effort has been included in the 
scope of the technical tasks. In this way, some allowance for program management and reporting can be assumed for each contractor.

\subsection{SYSTEM DESIGN AND DEMONSTRATION}

This task category comprises the work necessary to integrate the designs of the three major engine elements (engine, heat transport, combustor). Overall system performance analysis, design and specification of system's auxiliaries, test facility design and fabrication, and system testing and demonstration are also included in this category. Thus, it governs the interfaces between the major subsystems and comprises the principal effort once the subsystems are assembled. During the design phase, the output from this task will be a necessary Input to the design of the three major engine components.

The tasks included in this category are $2.1,3.1,4.1,5.2$ ?nd 5.3 .

\subsubsection{Task Descriptions}

Each of the tasks in the first task category, System Design and Demonstration, is discussed below in the order of the overall program phases. The major tasks in each phase are broken down into sub-tasks, and each sub-task is described.

\section{Phase II - Preliminary Design}

Task 2.1 - Preliminary System Design: The purpose of this task is to establish the epplication requirements and to relate these ta system performance requirements. Following definition of the engine and heat source process and state points, a preliminary system specification will 
-be prepared and preliminary cost and performance estimates w11l be made. Finally, a preliminary system layout will be produced.

Sub-task 2.1.1 - Define Application and Requitements: In order to produce a rational engine design, the intended application(s) must be identified in order to establish the necessary engine performance. Based upon the results of the conceptual design study, the intended application(s) will likely be those which can provide base-load operation of the engine and which can utilize a signiflcant fraction of the available engine waste heat. Following establishment of intended applications, the necessary performance parameters will be developed. These will include all system inputs and outputs, engine speed, power range, control requirements, fuel characteristics, cooling water temperatures, and special limitations.

Sub-task 2.1.2 - Define Process and State Points: Following establishment of engine performance requirements, the state points of the engine and heat source subsystem will be established. Mass and energy balances will be determined for the engine and combustion system. These will be used as inputs for the preliminary designs of the major subsystems and the system auxiliaries.

Sub-task 2.1.3 - Preliminary Mechanical Design: This task will include the design and specification of the engine auxiliaries, i.e., cooling water system, material handling system, ducting, emission controls, drives, packaging, and structural design. 
Sub-task 2.1.4 - Preliminary Electrical Design: This task will comprise the preliminary design and specification of the electrical generator and its associated controls.

Sub-task 2.1.5 - Preliminary Control: The control strategy for the Stirling engine, including the combustor, will be reviewed and considered against the application and engine system requirements. A preliminary controls strategy will be developed.

Sub-task 2.1.6 - Preliminary Systems Specifications: Following completion of the preliminary subsystems design, a preliminary systems specification will be prepared delineating the input requirements and the performance of the various subsystems, and specifying the purchased and fabricated components.

Sub-task 2.1.7 - Preliminary Cost-Performance Estimate: Based upon the preliminary systems specification, a preliminary system cost and performance estimate will be prepared.

Sub-task 2.1.8 - System Layout: Layout drawings will be prepared showing the major system components and the entire engine assembly. Preliminary estimates will be made of the structural requirements for the instailed system. 
Phase III - Final Design

Task 3.1 - Final System Design: The Final System Design task comprises final definition of the process and material and energy balances, specification of the mechanical and electrical auxiliaries, final control system design, preparation of the site plans and layouts, and procurement of long lead items.

Sub-task 3.1.1 - Final Process Design: Based on inputs from the preliminary designs of the major engine subsystems, a final process design will be prepared. The process design will establish the state points and material and energy flows for the engine system.

Sub-task 3.1.2 - Final Mechanical Design: Final designs and specifications will be prepared for all of the mechanical components.

Sub-task 3.1.3 - Final Electrical Design: Final designs and specifications will be prepared for all of the electrical components.

Sub-task 3.1.4 - Final Control Design: Final designs will be prepared for the engine power control and the combustion control system. Hardware designs and/or specifications will be prepared for fabricated and purchased control components.

Sub-task 3.1.5 - Final System Specifications: A final system specification will be prepared delineating the input requirements and the performance of the various sub-systems. All purchased and fabricated components shall be specified. 
Sub-task 3.1.6 - Site Plans: A suitable site will be located and final site plans will be prepared for the demonstration engine test facllity. Any construction work required prior to installation of components shall be defined.

Sub-task 3.1.7 - Layout Drawings: Final layouts w111 be prepared of the major engine components and the entire engine assembly.

Sub-task 3.1.8 - Procure Long Lead Items: Purchased equipment requiring long lead times will be Identified and procurement will be initiated as necessary.

Phase IV - Fabrication

Task 4.1 - Construct System Test Facflity: A system test facility will be constructed suitable for initial tests of the $\mathrm{FBC} /$ heat pipe sub-system, followed by testing of the complete con? fired engine. A separate, non-coal fired, engine test facility is discussed under the task category, Engine Design and Fabrication in Section 2.2.

Sub-task 4.1.1 - Site Preparation: Following preparation of the site plan, the site will be prepared for construction of the test facility.

Sub-task 4.1.2 - Procure Equipment: Procurement of the equipment initiated under Sub-task 3.1 .8 will be continued.

Sub-task 4.1.3 - Construction: All construction work shall. be performed as specifled by the site plan and facility design (Sub-tasc 3.1.6). 
Sub-task 4.1.4 - Installation: As equipment. is delivered to the site, and as construction activity is being completed, installation of system components will be initiated. Coal and sorbent storage and handling equipment, ash handling and disposal equipment, emissions control equipment, the stack, the electrical generator and engine auxiliaries will all be installed. The FBC and heat pipes are scheduled to be fabricated by mid-1984 and thus should also soon be available for installation in the test facility.

Sub-task 4.1.5 - Check-out Testing: Following installation of the FBC/heat pipe system, checkout testing will begin. Initially, this will comprise non-fired testing of the system. This will be followed by combustion tests using water cooled heat pipes and oil or gas, followed by eventual coal firing.

Phase V-Testing and Demonstration

The first part of the systems test will comprise fluidized bed combustion and heat pipe tests in the system test facility concurrent with engine/heat pipe tests in the engine test facility. Following approximately a year of such testing, the complete system will be assembled at the system test site. The coal fired large Stirling engine testing and demonstration will take place during the final year of the program.

Task 5.2 - FBC/Heat Pipe Tests: Testing of the FBC system using water cooled heat pipes will address the structural characteristics of the FBC module and heat pipes, as well as corrosion, combustion controls and emissions. Performance characteristics such as efficiency, load following and turndown will be measured. 
Task 5.3-Coal Fired Engine Demonstration: At the conclusiun of the FBC/heat pipe tests and the engine/heat pipe tests (Sub-task 5.1.1), the engine module will be installed in the FBC test facility, and complete coal fired engine tests will commence. Preliminary tests will be conducted to map engine performance, determine engine dynamics and control characteristics, and to measure the operating characteristics of the system. This task will be concluded by a series of engine demonstration tests which will include both performance and durability measurements.

\subsubsection{Schedule}

The schedule for the system design and demonstration effort is shown in Figure 4. The Phase II Preliminary System Design should be accomplished within the first twelve months of Phase II in order to provide system design specifications with sufficient lead time to coordinate the principal subsystem component designs.

The Phase III Final System Design will require approximately 18 months, but the final process design, i.e., definition of the process and state points, should be completed within 6 months, that is by the end of the sixth quarter. The site plan for the $\mathrm{FBC} /$ engine test facility should be produced by the end of the eighth quarter in order to provide sufficient time for bid preparation and concractor selection so that construction may begin at the start of the seventh quarter, with long lead items identified early enough for installation to proceed in the second quarter of FY84.

The principal system activity during Phase IV- Fabrication is construction of the system test facility. It is estimated that this will require approximately 


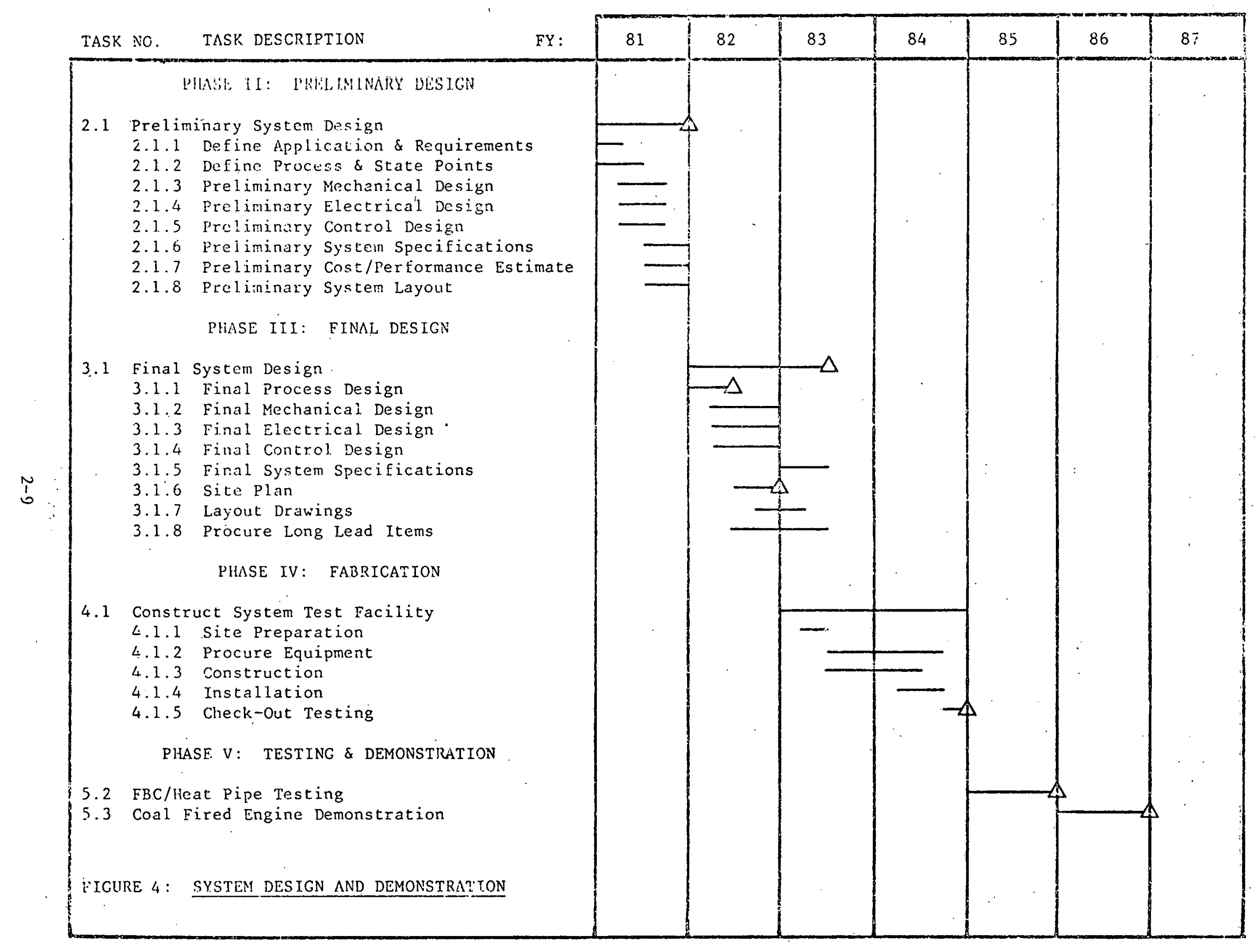


15 months; and that preliminary shake-down tests can take place during the last quarter of FY $84 \ldots$

The final testing and demonstration phase should require 24 months. Approximately 12 months will be spent in preliminary operation and testing of the FBC/heat pipe system. (These tests will be concurrent with engine/heat pipe testing in the engine test facility.) Once reliable FBC operation and reliable engine operation has been attained, the engine will be installed in the system test facility, and the final coal-fired engine testing and demonstration can commence. 
This task category comprises the work required to designiand construct : a $500 \mathrm{hp}$ Stirling engine module by 1985. It includes the construction and testing of two prototype modules. One would be a conventional 1iquid fueled engine, and the other would be integrated with a heat pipe. Initial testing of the heat pipe heated engine included in this task category would be by electric heating for simplicity. Following successful testing, the heat pipe heated engine wowld be installed in the system for coal fired engine testing and demonstration. However, this final demonstration is not included in this tasi category, but is included in the previous task category, System Design and Demonstration.

Because all of the engine work would be performed entirely by the engine designers, sowse engine related component development and supporting technology work is irsicluded in this section under Task 6. Also included is a design study of the direct fired by fluidized bed concept.

\subsubsection{Task Descriptions}

Each of the tasks in this category is discussed below in the order of overall program phases.

Phase II: Preliminary Design

Task 2.2 - Preliminary Engine Design: This task includes the preliminary design of the P-400 engine module for liquid fuel operation. Furthermore, this includes design izork for inverted orientation and adaptation of the 
heat pipe to the engine. Analysis of the drive unit and analysis of the interface between the cylinder block, the heater head and heat pipe will be performed in more detail.

\section{Phase III: Final Design}

Task 3.2 - Final Engine Design:: This task includes final design of both prototype engine modules and initial manufacturing as discussed below.

Sub-task 3.2.1 - Final Engine Design - Direct Fired: This task Involves final detail design of the complete Stirling engine for liquid fuel operation. This includes everything from the combustion system through the drive unit.

Sub-task 3.2.2 - Final Engine Design - Coal Fired: This task essentially involves the design of special components and of modifications required from the direct fired engine in order to accomodate inverted operation in combination with a heat pipe. Emphasis would be on the engine-heat pipe interface design.

Sub-task 3.2.3 - Initial Manufacturing: The manufacturing process would be initiated for long-lead items as necessary to enable testing of the direct fired engine to commence in mid-1984 and testing of the heat pipe heated engine to commence at the start of 1985.

\section{Phase IV: Fabrication}

Task 4.2 - Fabricate Engine: This task includes fabrication and,initial testing of the liquid fuel, direct fired engine. The design and fabrication 
of a test facility fring this testing and for initial testing of the heat pipe. heated engine is also included. Finally, fabrication of the heat pipe engine is included.

Sub-task 4.2.1 - Fabricate Direct Fired Engine: This task comprises fabrication ance assembly of the first engine module for liquid fueled testing.

Sub-task 4.2.2 - Test Direct Fired Engine: This includes initial tests of the liquid fireled engine in the laboratory. Tests include start-up and trimming, aceptance test, functional tests and endurance tests.

Sub-task 4.2.3 - Fabricate Coal Fired Engine: The fabrication of this engine is large ${ }^{1}$ y concurrent with fabrication of the direct fired engine. However, additimal manufacturing of components for inverted heat pipe operation is isuded.

Sub-task 4.2.4 - Construct Engine Test Facility: An engine test facility located in the engine designers' laboratory will be designed and constructed. This facility wast be suitable for initial tests of the liquid fueled engine, initiat tests of the electrically heated heat pipe engine, and further testing, of the liquid fueled engine. The facility includes an engine test rig with mounting structure, brake, electric power supply, and test instruentation.

Phase V: Testing and Demonstration

Task 5.1-Engine/Hestat Pipe Testing: This task includes laboratory testing of Lt? two gine modules in the engine test facility as discussed below. 
Sub-task 5:1.1:- Initial Test-Heat Pipe Engine: This involves testing wa the ef lectrically heated heat pipe engine in inverted orientation. Tests include start-up and triming, acceptance test ' functional tests and endurance tests.

Sub-task 5.1.2 - Follow-up Testing - Direct Fired: This includes tests of engine components both on separate bench tests and in the complete engine for redesign and improvement of components for use in the second generation engine.

Component Development and Supporting Technology

Task 6.1 - Engine: This includes development of components for use in the proposed demonstration engine. Heaters, sealing, auxiliaries and the drive system are subsystems which will be studied. Material analysis, analyses to understand the influence of engine scaling of existing components, stress analysis, fluid dynamic tests and motoring tests will be performed.

Task 6.4 - Design Study - Direct Fired by FBC Engine: This involves the conceptual design of a direct fired engine in combination with a fluidized bed. New engine concepts will be evaluated for their feasibility. A new heater tube arrangement will be studied for use in a fluidized bed combustor.

Task 6.5 - Advanced Concepts: The primary objective in this task is the design, fabrication and testing of advanced designs for engine components. The following component improvements may be envisioned:

1) Drive system - optimized dimensions, improved power t:ansmission.

2) Seal system - decreased seal friction losses, minimized pumping 


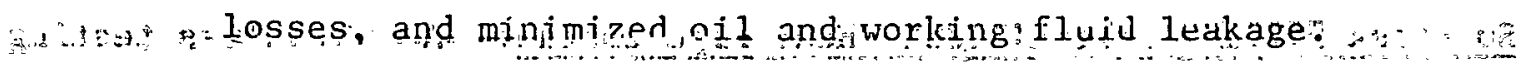

$\therefore$... 3) Heater $=$ minimization of flow losses improved heat transfer and temperature distribution, and minimization of dead volumes:

4) Regenerator - improved flow distribution, lower cost

5) Cylinder and Regenerator Housings - improved design resulting in lower heat losises

6) Stirling cycle - optimization of cycle component volumes, minimizing of flow losses, conduction losses and other losses (such as adiabatic losses, step-up losses, etc.)

\subsubsection{Schedule}

The schedule for the Engine Design and Fabrication effort is shown in Figure 5. The preliminary design will be completed in twelve months. The final design of the direct fired engine will be completed in twelve months in order to initiate fabrication of the longer lead items. The design of the heat pipe heated engine will proceed for eighteen months in order to obtain maximum benefit from experience gained in the small heat pipe engine tests (See Task 3.5.3 on the Overall Program Schedule, Figure 1).

Fabrication of the direct fired engine and the heat pipe heated engine will be concurrent. The direct fired engine will be completed in mid-1984 for initial testing. Thus the test facility must also be completed by mid-1984.

Following initial testing of the direct fired engine, the electrically heated heat pipe engine will be tested. Upon completion of these iests, further engine testing of components will occur in the direct fired engine. 







\subsection{HEAT PIPE DESIGN AND 'FABRICATION}

This task category comprises the work required to design and construct a two-stage gravity-assisted heat pipe suitable for the Stirling-FBC system. The heat pipe is unique from the engine and the $\mathrm{FBC}$ in that it interfaces directly with both of the other two major subsystems. The design of the heat pipe must thus be very sensitive to the interface requirements of both major subsystems.

\subsubsection{Work Descriptions}

\section{Phase II - Preliminary Design}

The preliminary design of the heat pipe heat transport system will require constani attention to the constraints imposed by the FBC and stirling engine to ensure the successful integration of the system.

During this eighteen month phase, in addition to designing the heat pipe system, the individual components must be developed where necessary and tested to ensure the viability of the design.

The primary heat pipe envelope must be evaluated with regard to sodium compatability, low hydrogen permeation, soundness of base material in the FBC and ease of fabrication. The protective coating must be shown to reduce, the erosive/corrosion action of the FBC on the base material. The internal wicking of the heat pipe must be shown to be capable of the required thermal performance while lending itself to low-cost fabrication techniques. 
The interface between the primary and secondary heat pipes must provide a good thermal and mechanical joint. This joint must be evaluated in terms of necessity to pass hydrogen through it if hydrogen accumulates in the primary heat pipe (See Volume 1, Section 3.2.1).

The secondary heat pipe must be evaluated in terms of the cost trade-off between the type of wick to be used on the multiple evaporators, the ease of wick fabrication, and the performance with respect to the heat flux and temperature drop through the wick. In addition, the secondary heat pipe.must be designed such that there is sufficient vapor velocity to sweep away any inert gas which may be blanketing the heater head tubes. The internal thermal Insulation near the water cooling jacket must be evaluated as well as the possible use of inert gas as a means of increasing the effectiveness of the internal insulation. Passive and dynamic control of the inert gas must also be examined.

During Phase II, two small heat pipe systems will be designed and fabrication will be begun. This work will start sufficiently after the inception of the preliminary design to allow for at least one 1teration in the selection of the more critical components, such as heat pipe envelope and evaporator protective coating material. (See Section 2.5)

\section{Phase III - Final Design}

The twelve-month final heat pipe design phase will continus to refine the design as discussed in Phase II. These efforts will culminate in a detailed design of the heat pipe heat transport system for a 500 hp coal irired FBC- 
Stirling engine-generator. One of the two small heat pipe heat transport systems designed and fabricated in Phase II will be integrated with an FBC and tested. The other will be integrated with a Stirling engine and electrically tested.

\section{Phase IV - Heat Pipe Fabrication}

This eighteen month phase will be used to fabricate three complete 500 hp heat pipe heat transport systems. One will be for testing in an FBC. One will be for integrating with a Stirling engine for electrical testing. The third will be for back-up in case of failure of either of the first two.

Long term testing of the small coal fired FBC/heat-pipe/Stirling engine will continue.

\section{Phase V - Demonstration}

Two of the three 500 BHP heat pipe transport systems fabricated in Phase IV will be integrated into their respective systems and the tests carried out. The heat pipe designers' effort in this phase is one of technical support and troubleshooting.

Component Development and Supporting Technology

This effort will include long term compatibility testing of sodium with several envelope materials with and without protective evaporator coatings under electrically and FBC heated conditions.

Envelope and coating materials will be searched for continuously and/or developed and tested for their long-term use in sodium heat pipes for a coal fired FBC. 
Improved heat pipe performance will be evaluated by the use of different wick structures, such as powder metallurgy wicks, and the reliability of the heat pipe heat transport system will be evaluated from the results of overtemperature and over-pressure tests and thermal cycle tests of the heat pipe system and mechanical joint.

\subsubsection{Schedule}

The heat pipe design and fabrication schedule is shown in Figure 6 . The deadlines and milestones shown reflect the requirements of the FBC and engine design tasks. For example, the final design is delayed sufficiently to receive input from the small engine testing. However, it is early enough to allow electrical testing after fabrication and before the heat pipes are integrated with the engine and the $\mathrm{FBC}$. 
Task No.

\author{
FY :
}

PHASE II: PRELIMINARY DESIGN

2.3 Preliminary Heat Pipe Design

2.3.1 Prinary Heat Pipe

2.3.1.1 Design Verification

2.3.1.2 Wick Evaluation

2.3.1.3 Material.s Evaluation

2.3.2 Heat Pipe Interface

2.3.2.1 Flange Design \& Evaluation

2.3.2.2 Interface Design \& Evaluation

2.3.2.3 Hydrogen Considerations

2.3.3. Secondary Heat Pipe

2.3.3.1 Wick Evaluation

2.3.3.2 Vapor Flow Evaluation

2.3.3.3 Inert Gas Evaluations

PHASE III: FINAL DESIGN

3.3 Final Heat Pipe Design

3.3.1 Primary Heat Pipe

3.3.1.1 Performance Evaluation

3.3.1.2 Wick Evaluation

3.3.1.3 Materials Evaluation

3.3.2 Heat Pipe Interface

3.3.2.1 Flange Design \& Evaluation

3.3.2.2 Interface Design \& Evaluation

3.3.2.3 Hydrogen Considerations

3.3.3 Secondary Heat Pipe

3.3.3.1 Wick Design \& Evaluation

3.3.3.2 Vapor. Flow Evaluation

3.3.3.3 Inert Gas Evaluations

FIGURE 5: HEAT PIPE DESIGN AND FABRICATION 
Task No.

FY:

\begin{tabular}{|c|c|c|c|c|c|c|}
\hline 81 & 82 & 83 & 84 & 85 & 86 & 87 \\
\hline
\end{tabular}

PHASE IV: FABRICATION

4.3 Heat Pipe Fabrication

4.3.1 Primary lieat Pipes - 3 sets

4.3.1.1 Manufacture

4.3.1.2 Electrical Test

4.3.2 Secondary Heat Plpe - 3 sets

4.3.2.1 Manufacture

4.3.2.2 Electrical Test

COMPONENT DEVELOPMENT \& SUPPORTING TECHNOLOGY

6.2 Heat P1pe

6.2.1 Long Term L1fe Tests

6.2.1.1 Sodium Compatibility

6.2.1.2 FBC Compatibility

6.2.2 Performance

6.2.2.1 Wick Development

6.2.2.2 Interface Development

6.2.3 Reliability

6.2.3.1 Thermal Cycle Tests

6.2.3.2 Over Temperature Tests

6.2 .4 Program Management

FIGURE 6: HEAT PIPE DESIGN AND FABRICATION (cont.) 


\subsection{COMBUSTIONON SYSTEM DESIGN AND FABRICATION}

The Program Plan for combustion system design and fabrication is based on the premise that fluidized bed combustion (FBC) will be the heat source for the demonstration system. While fluidized bed combustion may be considered state-of-the-art in that the technology has been demonstrated and commercial systems are available, it must be recognized that this is a resently emerged technology and that the design of the combustion system will require a good deal of developmental support. Accordingly, the design of the FBC system will be supported by an accelerated small-scale FBC testing program (See Section 2.5, Small Engine Tests) and a full-scale cold-flow test (See Section 2.4.2, below), which will be used to establish the full-scale fluid dynamic and heat transfer performance of the bed. In addition, it is recognized that certain problem areas may be uncovered during the design phase which may require experimental testing or development. Provision is made for this to occur either in rig tests as part of this task, or alternatively as part of the small engine test program.

\subsubsection{Task Descriptions}

Phase II - Preliminary Design

Task 2.4 - Preliminary FBC Design: The purpose of this task is to establish the overall FBC design concept and to identify combustor design problems and their solutions. The task is broken down into three major sub-tasks: Analytical Design, Cold-Flow Experiments, and Preliminary Hardware Design. 
Sub-task 2.4.1 - Analytical Design: In this task the conceptual design will be reviewed with respect to heat transfer, fluid dynamics, mass and energy flows, kinetics, etc., and using a mathematical model of the FBC combustor, a technical approach will be developed which meets the requirements identified in the System Design task.

Sub-task 2.4.1.1 - Review Conceptual Design: The Phase I FBC Conceptual Design will be reviewed from the standpoint of technical feasibility, economics, reliability, emissions, load-following ability, etc.

Sub-task 2.4.1.2 - Mathematical Model: To assist in analyzing the FBC design, a mathematical model will be developed to describe the mass and energy flows and the transfer processes within the FBC. As it would be beyond the scope of this engine demonstration program to develop a sophisticated simulation, only a simple, first-order model will be developed.

Sub-task 2.4.1.3 - Develop Approaches: Based upon the review of the Phase I Conceptual Design and identification of performance requirements, the technical approaches will be developed for the demonstration FBC module.

Sub-task 2.4.1.4 - Establish Development Requirements: While it is Intended that the design of the FBC should utilize state-of-theart technology, it is articipated that the special requirements of the Stirling application, including the sodium heat pipe interface, 
may require new developments in certain areas. These may be in the nature of materials, structural design, vibrations, dynamics, etc. These areas will be identified during the analytical design, and the development requirements will be identified so that they can be addressed either in the cold flow experiments, the smallscale engine tests, or in the component development and supporting technology tasks.

Sub-task 2.4.2 - Cold-Flow Experiments: Full-scale cold-flow experiments will be conducted to establish the basic fluid dynamic/heat transfer performance of the FBC module. These will help to establish relationships becween geonetrical design, velocities, mixing, heat transfer rates, particle sizes, etc., under conditions that most closely simulate the full-scale combustor. In conjunction with the small-scale hot (combustion) FBC tests, these experiments will provide a solid empirical basis for the design of the demonstration combustor.

Sub-task 2.4.3 - Preliminary Hardware Design: Following initial identification of the design approach in Task 2.4.1, a preliminary hardward design will be conducted to produce a layout of the FBC module and to idenify hardware design-related problems and their solutions.

Sub-task 2.4.3.1 - Layout Design: An FBC module design will :be produced at the layout level, based on inputs from the analytical design and the cold-flov experimental results. 
Sub-ta'sk 2.4.3.2 - Identify Problems and Solutions: It is anticipated that certain hardware-related problems may be identified in the course of the layout design. Approaches to solutions will be formulated, and these will be input either to the cold-flow experiments, the small-scale engine tests, or the component development and supporting technology task.

Sub-task 2.4.3.3 - Design Small Bed Tests: Near the conclusion of the analytical and hardware designs, the performance requirements and potential problem areas of the full-scale FBC module should be sufficiently defined to enable specification of the test configuration and conditions for the small-scale engine tests. These tests should be designed to provide the necessary inputs so that the $\mathrm{FBC}$ design can be finalized.

Phasi III - Fina1 Design

Task 3.4 - Final FBC Design: The final design of the FBC module will consist of parallel analytic and hardware designs. These will be based upon the previously concluded cold-flow experiments and the concurrent testing of the smal1-scale FBC taking place under Task 3.5 .

Sub-task 3.4.1 - Final Analyt1c resign: The final analytic design will address the mixing, heat transfer, fluid dynamics, chemical kinetics, etc., aspects of the FBC module to assure that the design will meet the performance requirements. 
Sub-task 3.4.1.1 - Specify Process: Based upon the results of the fina1 process design (Subtask 3.1 .1 ), the final design point and process of the FBC sub-system will be established.

Sub-task 3.4.1.2 - Establish Hardware Requirements: An analytical design will be conducted to determine the necessary operating conditions and the associated hardware requirements.

Sub-task 3.4.1.3 - Predict Performance: Based upon the preliminary analytical design of the FBC module, ils performance will be predicted in terms of flows, temperatures, pressures, and auxilliary power requirements. Estimates will be made of the dynamic performance and the permissible turn-down range.

Sub-task 3.4.2 - Final Hardware Design: Although this task will be essentially concurrent with the analytical design, it will rely strongly on the output of the analytical design and must be closely coordinated with it. It will also be paced to a significant extent by the results of the paraliel small-scale FBC tests.

Sub-task 3.4.2.1 - Final Layouts: Layouts will be produced showing the overall configuration of the FBC module and identifying its interfaces with the remainder of the system.

Sub-task 3.4.2.2 - Detailed Design: A final detailed design of the FBC module will be produced. This will include complete shop drawings and specifications in sufficient detail for fabrication of the module. 
Sub-task 3:4:2:3-Select Equipment: The purchased equipment utilized in the fluidized bed combustor (e.g., valves, feeders, lock-hoppers, etc.) will be selected once the requirements and interface specifications have been finalized.

Sub-task 3.4.3 - Procure Long-lead Items: Lead times for fabricated and purchased components will be identified, and a procurement schedule will be established to assure delivery of components when required. Procurement of long lead items shall be initiated as necessary.

Sub-task.3.4.4 - Continued Cold-F1ow Tests: Depending upon the outcome of the Phase II Cold-Flow Experiments, Sub-task 2.4.2, cold-flow testing, may be continued in support of the final design effort.

\section{Phase IV - Fabrication}

Task 4.4 - Fabricate FBC Module: The FBC module, sized for a nominal $500 \mathrm{hp}$ engine module, will be fabricated and delivered to the test site prior to assembly and installation. The physical size of the FBC module is not iarge, roughly. 2-3 cubic meters, and the hardware is not complex, so no special problems are anticipated in fabrication. The critical items are likely to be purchased components, such as solids-handling valves, feeders, etc. However, with adequate lead time, these should not be a problem either.

Fabrication of the FBC module would complete the Combustor Design and Fabrication sequence of tasks. Installation and testing of the combustor would be conducted under the System Design and Demonstration task (See Secticn 2.1.) 


\section{4 .2 Schèduie}

The schedule for the Combustion System Design and Fabrication effort is shown in Figure 7. Preliminary design is expected to require 18 months, paced by the cold-flow experiments. The Phase III Final Design can be accomplished within 12 months, and should be complete by the second quarter of FY83. The pacing items for the final design are the Small Engine FBC tests, plus any continued cold-flow testing and/or component development. Twelve months have been allowed for fabrication of the FBC module, which leaves the final six months of the fabrication phase for installing the module and check-out testing. 


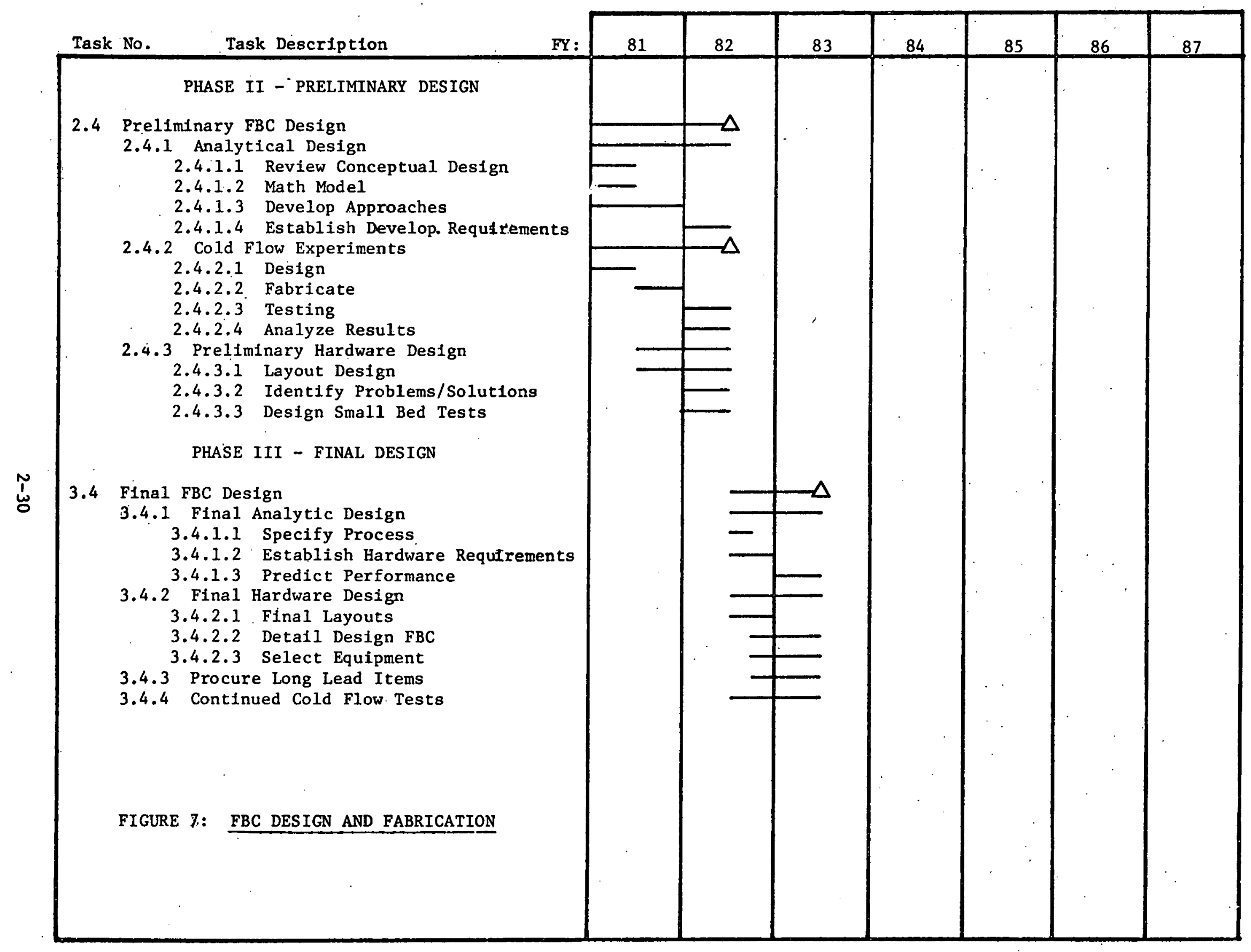




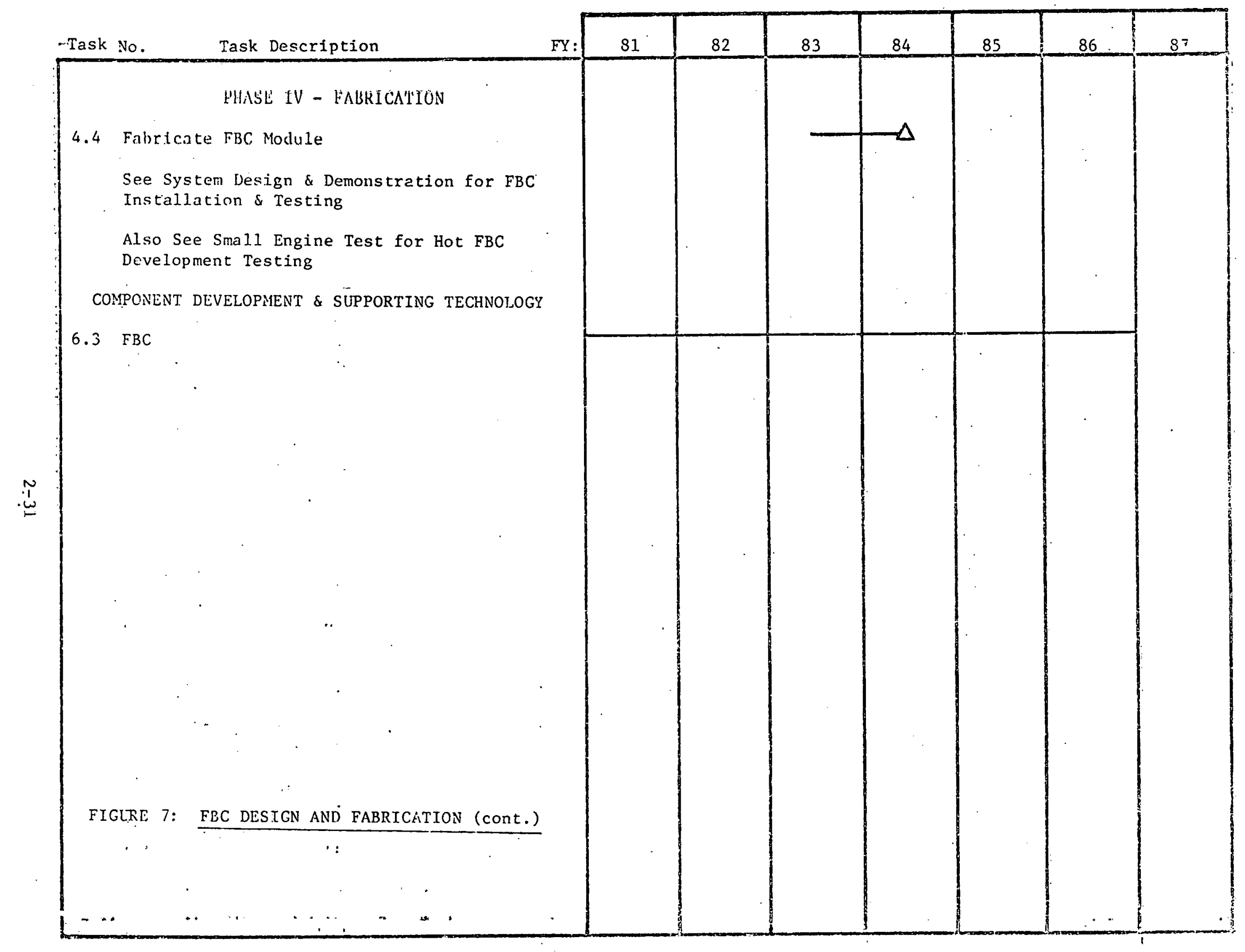




\subsection{SMALL ENGINE SYSTEM}

This task category comprises the work required to design, build, test and thus demonstrate a small coal fired stirling engine. The primary impetus for this work is to provide prior experience with coal fired Stirling engines so as to provide minimum technical risk in the large engine development prograin. The small system will serve as a test-bed to verify the design principles upon which the large engine system will rely. Furthermore, it can serve as a low-cost materials testing ground which accurately simulates the envi.ronment of the large engine system. This is especially useful for FBC and heat pipe design. Furthermore, the small system can be used to test components, as well as to teșt advanced concepts.

\subsubsection{Task Descriptions}

\section{Phase II - Preliminary Design (of large engine)}

The work in Phase II is particularly critical to the overall program plan because of timing. It is essential to design and build working hardware quickly which can be tested in order to provide guidance in the large system design.

Task 2.5 - Design and Fabricate - Small System: This task involves the design and fabrication of a small engine system. A proven Stirling engine (e.g., USS $\mathrm{P}-40$ ) would be used with minor modifications. The detall design of the FBC and heat pipe would be based on the results of the conceptual design phase.

Sub-task 2:5.1 - System: Th:s sub-task is analogous to the System Design and Demonstration effort (See Section 2.1) in Phases II through IV. 
However, because of the smaller size and simpliclty of the small syslem, the effort can be condensed into 18 months. At the end of this sub-task, the system w111 be ready for installation of the FBC and heat pipe subsystems for testing.

Sub-task 2.5.2 - Engine: This sub-task involves all the design and fabrication work which is required prior to engine/heat pipe subsystem testing (See Task 3.5.3.).

Sub-task 2.5.2.1 - Engine Components Design and Fabrication: This Involves design of $\mathrm{P}-40$ components required for inverted operation and for the heat pipe interface. A new Iubrication system is required, as are changes to the cooling system, the heater head, and the heat pipe-engine interface. Changes in the cylinder block could be required. This task also includes manufacturing of all engine components.

Sub-task 2.5.2.2 - Engine Component Testing: As soon as critical parts are fabricated, they would be individually tested in the laboratory. Tests of bellows, heater tubes, seal system, etc., will be performed as well as motoring tests of the complete drive unit.

Sub-task 2.5.2.3 - Engine/Heat. Pipe Test Facility: Several changes to existing engine testing facilities are required for the electrically heated engine/heat pipe tests. A1! required components, instrumentation, etc., would be designed, procured or fabricated, and assembled. 
Sub-task 2.5.3 - Heat Pipe: The two-stage gravity-assisted heat pipe concept discussed in volume one of this report would be used. The design of the primary heat pipe would probably not change substantially from the large engine design, but rather the number of primary heat pipes would be reduced. Thus, successful design and testing here would provide working hardware for the large engine system as we11. Considerable experience would be gained in wick design, heat pipe interface design and engine interface design.

Sub-task 2.5.4 - FBC: This task involves the design and fabrication of a small FBC. Because the small system would primarily be used as a development tool, this FBC should be built for easy assembly and disassembly, and be flexible enough to permit changes.

\section{Phase III: Final Design (of large engine)}

Task 3.5 - Subsystem Tests - Sma11 System: The purpose of this task 1s to provide early test results of the $F B C$, heat pipes and engine during the final design of the large engine system.

Sub-task 3.5.1 - Install FBC/Heat Pipes: This involves installing the fabricated $\mathrm{FBC}$ and heat pipes into the system. Checkout testing would begin immediately following installation.

Sub-task 3.5.2 - Test FBC/Heat Pipes: After some initial low temperature tests, the bed would be fired by oil or gas, followed by coal. The secondary heat pipe would be water cooled during the high temperature tests. The tests to be performed would be spciffied by the designers of the large FBC. Some examples are: heat transfer tests, espectally 
to determine the radiation effect; elutriation tcsts; peifurmance tests (turndown, load following, efficiency); emissions tests; distributor plate design tests; heat pipe materials and coatings tests; etc.

Sub-task 3.5.3 - Test Engine/Heat Pipe: The small engine would be heated by an electrically fired two-stage heat pipe. This would be accomplished by electrically heating the evaporator of the primary heat pipe. In this way the performance of the heat pipe heated engine could be accurately measured, and the engine/heat pipe interface would be tested prior to assembly in the FBC. Testing includes start-up tests, acceptance test and trimming, functional tests and accelerated endurance tests.

\section{Phase IV: Fabrication (of large engine)}

Task 4:5 - Sma11 System Demonstration and Testing: In this task the complete small FBC heat-pipe/engine system would be tested.

Sub-task 4.5.1 - Demonstrate Small Coal Fired Engine: Once successful subsystem testing (Sub-tasks 3.5 .2 and 3.5 .3 ) is finished, the engine would be installed in the small system tcst facility. Testing of the coal fired Stirling engine would then begin. It is expected that successful demonstration of the entire system could be accomplished shortly after subsystem testing is completed.

Sub-task 4.5.2 - Continue Testing: After demonstration testing is over, the small engine will provide an excellent experimental facility for system performance testing and component development. Some examples might be overall performance tests, emissions tests, temperature measurements, material tests, heat pipe testing, etc. This task is 
designed to accomodate such requirements.

Phase V: Testing and Demonstration (of large engine)

Task 5.4-Component Testing in Small System: While the large engine testing is underway, continued testing of components, new concepts, new materials, etc., could help improve the large engine system.

\subsubsection{Schedule}

The task schedule for the Small Engine System is shown in Figure 8. The work taking place in the Small Engine System leads the analogous work in the Large System by one phase. The Small Engine System plan is fastpaced, with design leading directly into fabrication, which in turn leads into subsystem testing, and finally demonstration of the complete system. The most important milestones are the $\mathrm{FBC} /$ heat pipe and the heat pipe/engine tests, followed by the complete coal fired engine demonstration. These will provide important inputs to, or confirmation of, the various large engine component and system designs in timr for any required modifications or final selections to be made. 


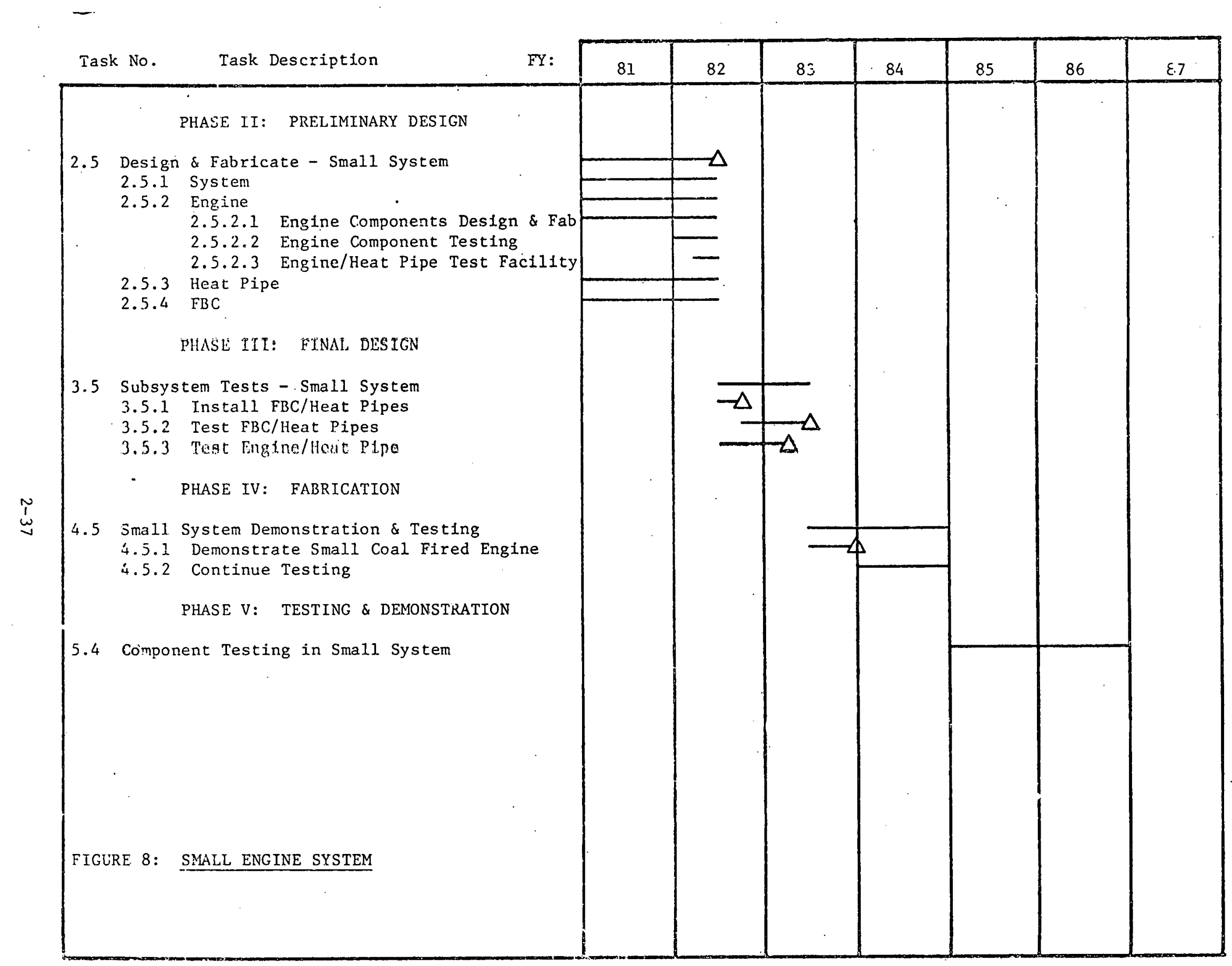




\section{DETAILED COST BREAKDOWN}

For simplicity, the detailed breakdown of estimated costs is presented by task in numerical order (See Figure 9). For each task described in. Section 2, Detailed Program Plan, estimates for personnel and materlals and other direct costs are presented. In some cases where it was considered enlightening, the cost breakdown is given at the third sub-task level.

There are several important assumptions which were used to develop this cost estimate. First and foremost, all cost estimates are given in constant 1980 dollars, regardless of the time when the task will be performed. Secondly, while the system, FBC, and heat pipe work are estimated based on American labor costs, all engine work is based on Swedish working conditions and a Swedish Orown to U. S. Dollar exchange rate of $4.16 \mathrm{Sw}$ Cr to $\$ 1.00$. Also note that the small engine system work is based on the use of an. existing proven Stirling engine, such as the United Stirling P-40 engine. Finally, it should be noted that the program management and reporting costs are allocated among the various technical tasks.

In Figure 9, all dollar estimates were rounded off to the nearest $\$ 10,000$ to reflect the level of accuracy of the estimates. Labor costs were estimated by the use of five different labor categories (engineering manager, engineer, design engineer, technician, shop), and thus the labor rate is different from task to task depending on the type of labor required.

Also in Figure 9, the labor estimates for fabrication of engine components may appear to be very low. Since angine fabrication cost is made up of 


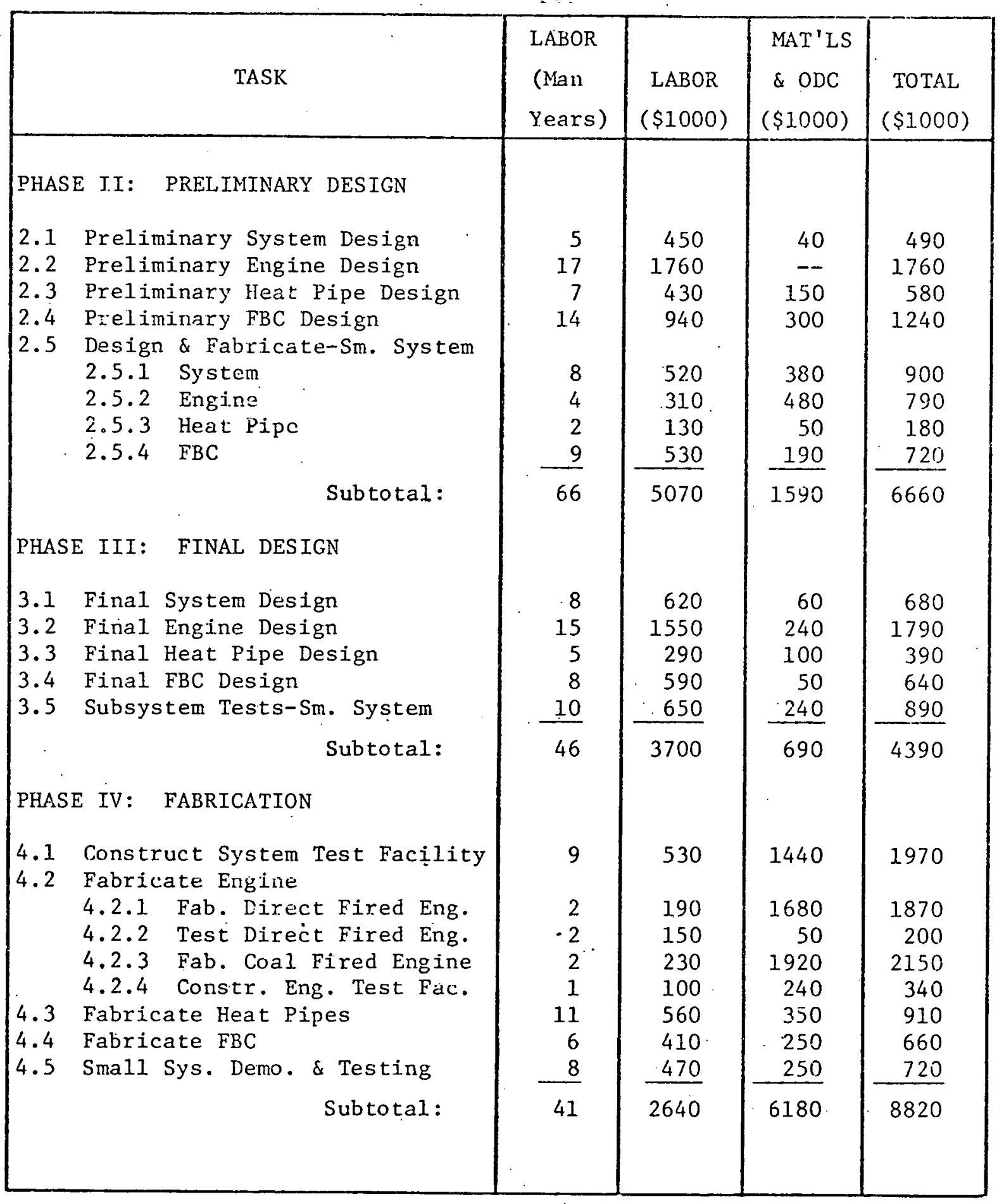

FIGURE 9: PROGRAM COST BY TASK 


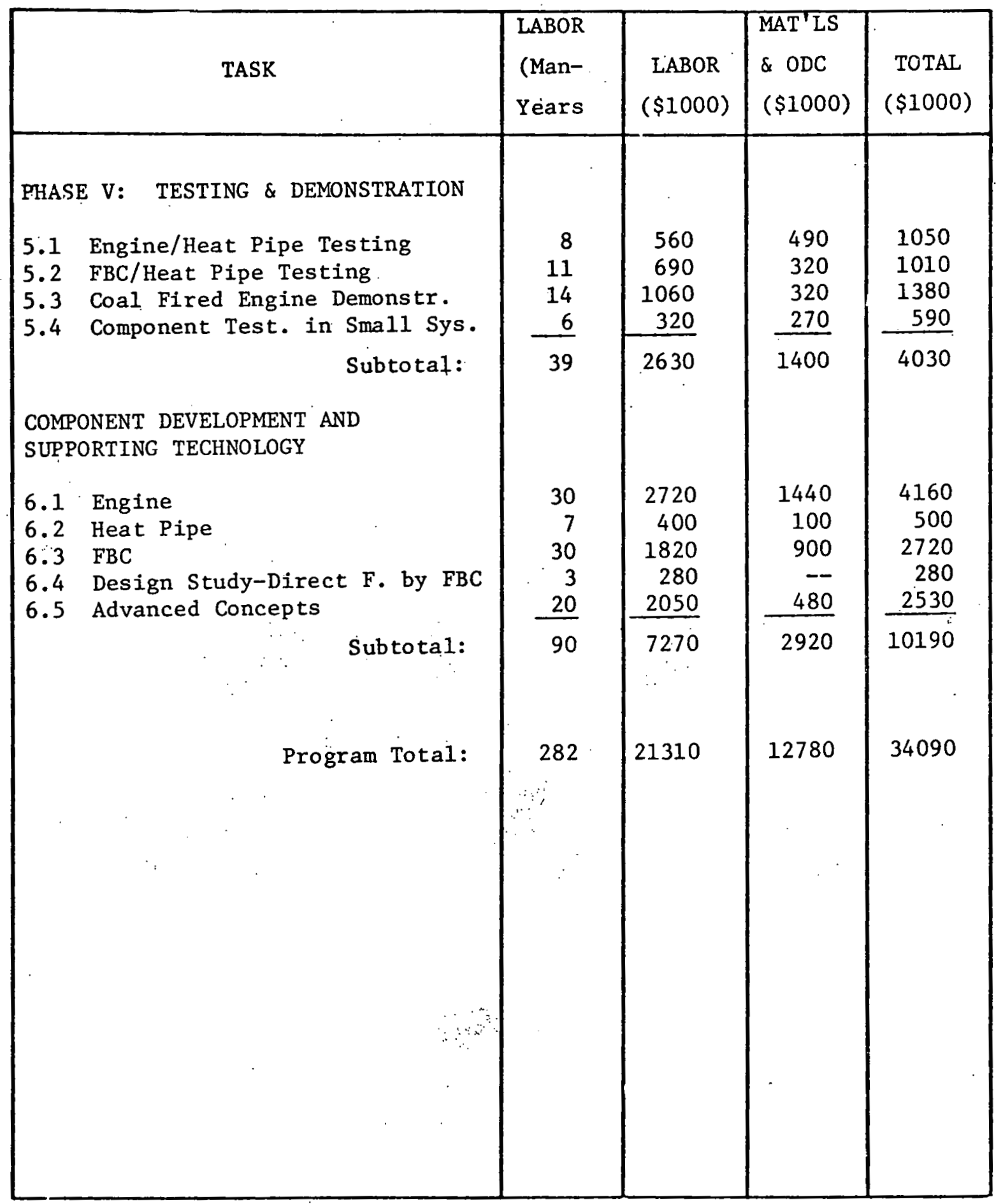

FJGURE 9: PROGRAM COST BY TASK (cont.) 
fabricated parts, purchased parts, subcontracted items, etc., it made more sense to estimate the complete fabricated cost of the first engines, including all labor. Tnus the materials and other direct costs column for Tasks 4.2.1, 4.2.3 and 2.5.1 includes estimates for all labor other than for program management. 